\title{
SIMULAÇÕES DOS CAMPOS DE VENTOS EM SUPERFÍCIE SOBRE MOÇAMBIQUE
}

\author{
Nelson Mário Banga ${ }^{1,2}$, Emerson Mariano da Silva ${ }^{1}$, Alexandre Araújo Costa ${ }^{1}$ \\ ${ }^{1}$ Universidade Estadual do Ceará (UECE) \\ ${ }^{2}$ Faculdade de Engenharia Ambiental e de Recursos Naturais (FEARN) - Unizambeze \\ 1nlsnbanga@gmail.com
}

\section{RESUMO}

Este trabalho apresenta resultados da avaliação de desempenho do modelo atmosférico regional RAMS6.0 nas simulações dos campos médios de ventos em superfície sobre as regiões de Moçambique.

\begin{abstract}
This paper presents the results of performance evaluation of the regional atmospheric model RAMS6.0 in the simulations of mean fields of the surface winds over the regions of Mozambique.
\end{abstract}

\section{INTRODUÇÃO}

A avaliação desempenho dos modelos de previsão de recursos eólicos sempre esteve no centro das discussões de vários pesquisadores, sobretudo dada à necessidade de se encontrar melhores estimativas de vento para efeitos de aproveitamento como fonte de energia. Todavia, os métodos estatísticos como os descritos em De Maria et al. (2008) têm sido amplamente utilizados para avaliar o desempenho das simulações. Neste trabalho, avaliou-se o desempenho de simulações climáticas dos campos médios dos ventos sobre as regiões de Moçambique (Norte, Centro e Sul), para o período de dezembro de 1985 a novembro de 2005 . 


\section{MATERIAIS E MÉTODOS}

Neste trabalho, foi usado o modelo atmosférico regional RAMS6.0 (PIELKE et al., 1992), forçado pelos campos de saída do modelo acoplado de circulação global HadGEM2ES (Hadley Centre Global Environmental Model version2- Earth System) através da técnica de redução de escala - dynamic downscaling (Figura 2). O domínio das simulações possui uma resolução espacial horizontal de $15 \mathrm{~km}$ x $15 \mathrm{~km}\left(0,13^{\circ}\right.$ long x $\left.0,13^{\circ} \mathrm{lat}\right)$.

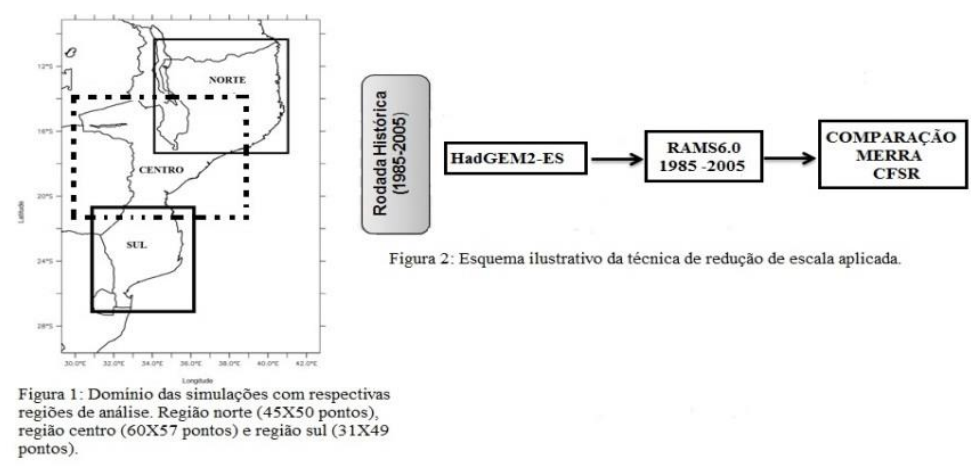

Os campos de ventos simulados foram comparados aos obtidos em reanálises do CFSR (0,3long x $0,3^{\circ}$ lat), e do MERRA ( $0.6^{\circ}$ long x $0.5^{\circ}$ lat). Para o efeito, foram usados os índices estatísticos descritos em De Maria et al. (2008): Viés, Erro Quadrático Médio $(E Q M)$; Coeficiente de Correlação $(r)$ e o Índice de Concordância $\left(I_{c}\right)$.

\section{RESULTADOS E DISCUSSÕES}

Os campos de ventos simulados apresentam padrões semelhantes aos apresentados pelas reanálises do CFSR e MERRA (Figura 3). Porém, uma exceção é verificada nos meses de janeiro a abril sobre as regiões centro e sul, em que se tem estimativa de diminuição da velocidade dos ventos em relação às reanálises. Adicionalmente, observa-se que o modelo superestimou os valores das reanálises do CFSR em todas as regiões, sendo que somente subestimou às reanálises do MERRA na região norte. 


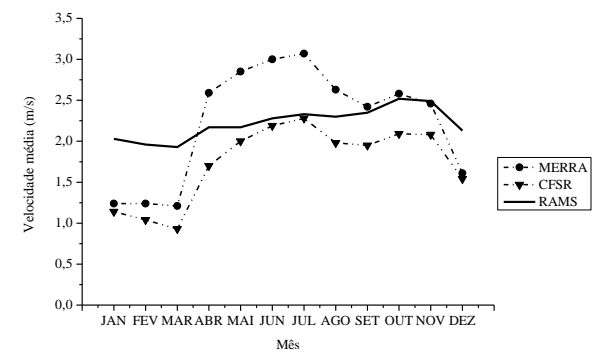

a)

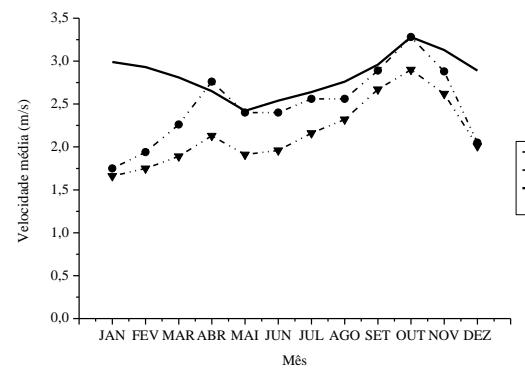

b)
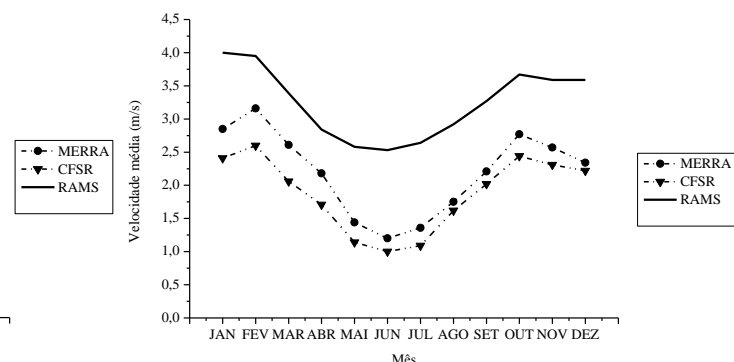

c)

Figura 3 - Comparação entre as velocidades de ventos simuladas (linha sólida) com as reanálises do CFSR e MERRA (linhas tracejadas): $\quad$ (a) região norte, (b) região centro, (c) região sul.

Na Tabela 1, observa-se que os campos médios de ventos simulados apresentaram um EQM>0,8 m/s em relação às reanálises do CFSR e MERRA. A região sul apresentou um índice de concordância classificado de péssimo (CORTÊS,2004) entre os campos de ventos simulados e as reanálises, o que sugere que o modelo apresentou fraco desempenho em simular os campos médios de ventos sobre esta região.

Tabela 1 - Índices estatisticos médios para o período de dezembro de 1985 a novembro de 2005

\begin{tabular}{|c|c|c|c|c|c|c|}
\hline & \multicolumn{2}{|c|}{ NORTE } & \multicolumn{2}{|c|}{ CENTRO } & \multicolumn{2}{|c|}{ SUL } \\
\hline & $\begin{array}{c}\text { RAMS } \\
\text { vS } \\
\text { CFSR }\end{array}$ & $\begin{array}{c}\text { RAMS } \\
\text { vS } \\
\text { MERRA }\end{array}$ & $\begin{array}{c}\text { RAMS } \\
\text { vs } \\
\text { CFSR }\end{array}$ & $\begin{array}{c}\text { RAMS } \\
\text { vs } \\
\text { MERRA }\end{array}$ & $\begin{array}{c}\text { RAMS } \\
\text { vs } \\
\text { CFSR }\end{array}$ & $\begin{array}{c}\text { RAMS } \\
\text { vs } \\
\text { MERRA }\end{array}$ \\
\hline $\begin{array}{c}\mathrm{b} \\
(\mathrm{m} / \mathrm{s})\end{array}$ & 0,48 & $-0,01$ & 0,6 & 0,39 & 1,37 & 1,12 \\
\hline $\begin{array}{r}\text { EQM } \\
(\mathrm{m} / \mathrm{s})\end{array}$ & 0,8 & 0,9 & 0,85 & 0,89 & 1,5 & 1,43 \\
\hline $\mathrm{r}$ & 0,72 & 0,61 & 0,91 & 0,78 & 0,92 & 0,8 \\
\hline $\mathrm{I}_{\mathrm{c}}$ & 0,58 & 0,53 & 0,72 & 0,63 & 0,23 & 0,18 \\
\hline
\end{tabular}




\section{CONCLUSÕES}

O modelo RAMS foi capaz de reproduzir os padrões médios dos campos dos ventos obtidos nas reanálises do CFSR e MERRA, embora algumas diferenças de padrão tenham sido encontradas nas regiões centro e sul, nos meses de novembro e março. Os índices estatísticos avaliados apresentam valores que caracterizam um desempenho satisfatório do modelo em simular os campos médios dos ventos sobre as regiões de Moçambique, embora o desempenho tenha sido menor sobre a região sul do país.

\section{AGRADECIMENTOS}

Os autores agradecem ao MCT-Moz através da concessão da bolsa, ao CMACFA e a Unizambeze- FEARN.

\section{BIBLIOGRAFIA}

CORTÊS, F. C. Obtenção e validação de modelos de regionalização de vazão na bacia do rio dos Bois, Estado de Goiás. 2004. 56f. Dissertação (Mestrado em Ciências Agrárias) Universidade de Brasília, Brasília, 2004.

De MARIA, P. H. S.; COSTA, A. A.; SOMBRA, S. S. Modelagem numérica em alta resolução para previsão de geração de energia eólica no Ceará. Revista Brasileira de Meteorologia, v. 23, n. 4, p. 477-489, 2008.

PIELKE, R. A. R., COTTON W. R., WALKO R. L., TREMBACK C. J., LYONS W. A., GRASSO L. D., NICHOLlS M. E., MORAN M. D., WESLEY D. A., LEE T. J., and COPELAND J. H. A comprehensive meteorological modeling system RAMS.Meteorology and Atmospheric Physics, v. 49, n. 1-4, p. 69-91, 1992. 